\title{
Social Media Use and Social Integration of Ethnic Minorities in Germany: A New Interdisciplinary Framework
}

\author{
By Alexandra Mittelstädt \\ Özen Odag ${ }^{\dagger}$
}

Faced with an increasingly diverse society, Germany is challenged with the integration of different ethnic minorities. Previous studies have shown that mass media can play a crucial role in the integration process. However, what has not been extensively researched in this context yet are social media in particular. What is missing in research is a conceptual framework to better understand the interplay between social media use and integration. Therefore, this paper focuses on social media use and the integration of ethnic minorities into German society from a conceptual perspective. What is proposed here is a new interdisciplinary conceptual framework which clearly distinguishes between integration that happens in society ("offline") and integration that happens in virtual communities ("online").The aim of this paper is to expand integration research to social media use as well as to offer a new interdisciplinary conceptual framework for further empirical research.

Keywords: social media use, social integration, ethnic minorities

\section{Introduction}

With increased migration many societies, including Germany, have become more ethnically and culturally diverse. In 2013, $19.7 \%$ of the German population had a so-called migration background (Statistisches Bundesamt, 2013, p. 39). A migration background includes (1) people who migrated to Germany; (2) people who were born as foreigners in Germany; and (3) people born as Germans in Germany with at least one migrated parent or as a foreigner born parent in Germany (Statistisches Bundesamt, 2013, p. 5-6). The percentage even raises to $27.8 \%$ when only the population under 35 years is taken into account (Statistisches Bundesamt, 2013, p. 39). So Germany's society will most likely become even more diverse. This development poses challenges to the German society in terms of the integration of different ethnic minorities.

Previous research has shown that mass media can play a significant role in the integration of minorities into society. Nowadays, particularly social media have started to play a growing role in the social lives of many people, especially of the younger generations. In Germany, $60 \%$ of the migrant population indicated to be registered on a social networking site; among the 14-

${ }^{*}$ PhD Fellow, Bremen International Graduate School of Social Sciences, Germany.

${ }^{\dagger}$ University Lecturer of Empirical Methods, Jacobs University Bremen \& Coordinator of the Methods Center, Bremen International Graduate School of Social Sciences, Germany. 
29 years olds it is even $80 \%$ (Müller \& Beisch, 2011, p. 501). The growing availability of social media and their specific characteristics are influencing social relations and society on a large (Mejias, 2010, p. 604). Since social media are web-based and focus in particular on social interaction and user generated content, users can easily connect to other people and share content regardless of the geographical distance (Kaplan \& Haenlein, 2010, p. 61). Thus, it allows users to engage in conversations without being face-to-face with others and can also "create a sense of belonging to a greater social network beyond one's local community" (Sawyer \& Chen, 2012, p. 152-154). This has been further reinforced with the proliferation of mobile technologies, such as smartphones and tablets, that have made it possible to be online everywhere and all the time.

Nevertheless, despite its growing popularity and global reach, social media in relation to the integration of ethnic minorities into society is still an underresearched field, especially in Germany. But with the technological and cultural developments, it has become of great social relevance to further examine the relationship between social media use and the integration of ethnic minorities in order to better understand the social implications of social media use in the process of integration. This paper presents a new interdisciplinary conceptual framework to examine the interplay between social media use and integration.

\section{Literature Review}

\section{Integration Research in Germany}

Integration is a "complex, multilayered concept subject to contradictory interpretation", as Geißler and Weber-Menges (2009 p. 27) point out. What they criticize is the fact that the concept "integration" is often mistaken as "assimilation", which is predominant in German research on migration (Geißler \& Weber-Menges, 2009 p. 28; Esser, 2001). Assimilation, however, is specifically referring to the adjustment of the minority group to conform to the majority group. Integration, on the other hand, refers to a mutual process of adjustment of all groups involved with no pre-given direction. It entails opportunities and intentions of actions that result in certain forms, of which one outcome can be assimilation (Essser, 2001, p. 25). Such a misconceptualization leads to misunderstandings not only in research but also in political discussions. Researchers and politicians may describe successful integration when migrants fully adapt to the host society and neglecting their cultural roots, when this is really assimilation and not integration. This conceptual misunderstanding comes at costs to ethnic minorities. They are left with only one option for joining the host society; namely, giving up their roots and blending in the new culture. By this, Germany is neglecting the idea of multiculturalism and losing an opportunity to create a sense of belonging beyond ethnicity. To overcome this conceptual confusion, this paper provides 
a clear conceptual framework to examine integration in the "offline" context, which will be society, and in the "online" context, which will be the virtual community on social media platforms.

\section{(Social) Media Use and Integration of Ethnic Minorities}

Research on ethnic minorities and their media use in context of integration is still a rather young field. In particular in Germany, this research area has only been focused on in the last two decades and is still full of gaps (Piga, 2007, p. 210). The growing interest in this field can be explained by the increasing role media play in the daily life of ethnic minorities and their integration (Worbs, 2010, p. 10; Piga, 2007). So far, research has shown that there is a relationship between media use and integration of ethnic minorities. There are studies which have shown that media use was a consequence of the integration status of a person (Weiss \& Trebbe, 2001; Trebbe, 2007). So depending on the integration status, a person would choose to use a certain type of media. Other studies, for instance by Peeters \& d'Haenens (2005) and Brendler et al. (2013), discovered a different direction of influence, namely that media use has effects on the outcome of the integration status of a person. What these studies show is that the direction of causality of media use and integration is still unclear.

In the recent years, research has started also to focus on social media use of ethnic minorities. Research has identified that integration within traditional social networks, e.g. into a local community or society, is related to social connectedness (Grieve, Indian, Witteveen, Tolan, \& Marrington, 2013, p. 604). Current forms of social media provide opportunities for such social connectedness. What needs to be examined further is whether social media can play a significant role for ethnic minorities and their integration process.

Several studies have explored the impact of social media on acculturation, a concept related to integration that refers to the degree of cultural change (Cabassa, 2003, p. 128). On the one hand, social media can resolve cultural differences by connecting people from different ethnic groups in society, which can positively influence the integration (Park, Song, \& Lee, 2014, p. 143). On the other hand, social media can also enforce in-group cohesion as individuals from ethnic minorities can connect to people from their "home" country and communicate in their "home" language which might negatively influence their integration into society (Peeters \& d'Haenens, 2005, p. 202).

So it has been shown that social media can facilitate the adjustment to a new culture by allowing interaction and communication with both people from the home country and the new host country (Sawyer \& Chen, 2012, p. 164; Park et al., 2014, p. 142). Furthermore, it was discovered that social media play a high integrative role in terms of intra- and inter-ethnic relationships among adolescent immigrants (Brendler et al., 2013). Although, social media seem to affect integration, data are still limited to draw any conclusions on the actual direction of influence (Shuter, 2011, p. 228). Therefore, a new interdisciplinary approach to social media use and integration is proposed here. 


\section{A New Conceptual Integration Approach}

Drawing on theories from three different disciplines (media and communication studies, sociology, and psychology), this paper aims to integrate the Uses and Gratifications Theory, Esser's dimensions of social integration, and Berry's acculturation model in order to examine the role of social media use in the integration of ethnic minorities. Each of these theories and concepts are described individually first and then integrated into one framework.

\section{Uses and Gratifications Theory and Social Media}

A central theory which frames the overall approach in this paper is the Uses and Gratifications Theory (U\&GT). This theory originates from the communication studies and is a counterstream to the media effects stream. Contrary to the media effects perspective, which focuses on the influences of media on the audience, the U\&GT is concerned with the reasons and motivations of individuals for using certain types of media. Its main assumption is that individuals actively and deliberately use media to gratify their needs. Thus, it helps to explain how people use media to gratify their needs, their motives for media use and the consequences that follow from these needs (Katz, Blumer, \& Gurevitch, 1974, p. 20).

In particular for social media, which allows for much more interactivity and user generated content, U\&GT offers a useful alternative to the media effects perspective (Raacke \& Bonds-Raacke, 2008). In the context presented here, this perspective will help to better understand how ethnic minorities use social media to gratify their needs (e.g. need to connect with other people) what their motives are (e.g. to connect with people from the "host" country in order to improve language skills), and the consequences that follow from their needs (e.g. integration).

Most of the studies in Germany have focused mainly on the media use of migrants and media effects, describing only media use habits or frequencies and the influence of the media on the individual or the audience (Brendler et al., 2013). In the German context, little research has focused on the motivations and gratifications that migrants link to using certain media forms. However, with social media, where the individual is no longer only a passive consumer but an active participant, it becomes even more crucial to examine what people do with media, instead of only looking at what media do to people. Furthermore, as U\&GT is rooted in media and communication studies, applying this theory to integration will be a new approach in this field that will offer an original and useful interdisciplinary perspective.

\section{Berry's Acculturation Model}

An often used model in psychology when it comes to migrants in society, is Berry's acculturation model (Berry, Phinney, Sam, \& Vedder, 2006). People 
from ethnic minorities or with a migration background often (but not necessarily) are exposed to different cultures; different from the majority culture of the country they live in. These people might experience some kind of conflict or struggle and might have to find a strategy on how to best adapt to their situation. Berry et al. (2006) constructed a model where he identified four different strategies of how people deal with cultural change when they migrate to a new country (Table 1).

Table 1. Berry's Acculturation Model

\section{Berry's Acculturation Typology}

\begin{tabular}{|l|l|}
\hline Assimilation & Integration \\
+ accepts new culture & + accepts new culture \\
- rejects old culture & + maintains old culture \\
\hline Segregation & Marginalization \\
- rejects new culture & - rejects new culture \\
+ maintains old culture & - rejects old culture \\
\hline
\end{tabular}

Source: Own adaptation, based on Berry et al. (2006, p. 306).

One strategy is assimilation which is when the immigrant accepts the new culture and rejects the old "home" culture. The opposite strategy would be segregation. This is when the immigrant holds on to the "home" culture and completely rejects the new culture. When the immigrant rejects both the new and old culture, we speak of marginalization. According to Berry's model, integration, which involves both cultural maintenance and participation in the wider society, is associated with the most positive adaptive outcomes (Berry et al., 2006, p. 306). Here, integration is one of four possible strategies of acculturation. This is important to point this out, because in the next section, integration is described as the overall process and not as an outcome.

\section{Dimensions of Social Integration}

Integration, generally speaking, is the cohesion of single parts into a whole (Esser, 2001, p. 1). Applied to society, Lockwood (1964) makes two distinctions: system integration and social integration. System integration refers to "the orderly or conflictful relationships between the parts", whereas 
social integration means "the orderly or conflictful relationships between the actors" of a social system (cited by Esser, 2001, p. 3). Thus, the focus in system integration is on the integration of the society's system as a whole, while social integration focuses on the integration of individual actors into the system (Esser, 2001, p. 3). Conceptually, system integration and social integration are independent from each other and can therefore be researched separately (Esser, 2001, p. 11).

The focus in this research is exclusively on social integration. Esser identifies four dimensions of social integration: acculturation, interaction, identification, and placement. These dimensions are illustrated in Figure 1.

Figure 1. Dimensions of Social Integration

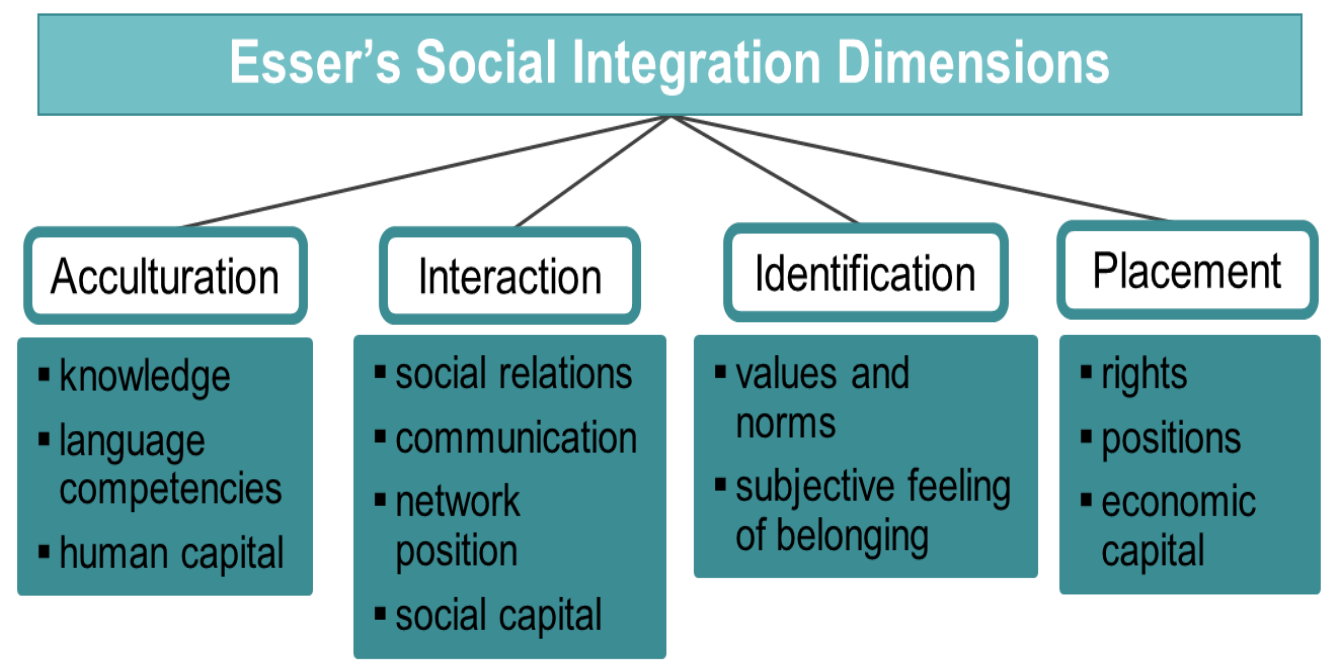

Source: Own adaptation, based on Esser (2001, p. 16, Fig. 2).

These four dimensions contain the key aspects of social integration. The first dimension depicted in Figure 1 is acculturation which includes cultural knowledge and language competencies needed for interaction and is part of the socialization process into a society. Interaction refers to the building and maintaining of social relationships in daily life. Identification encompasses the emotional relationship between the actor and the society, a subjective feeling of belonging. Placement here means the position in a society and the rights gained with it, may it be by citizenship or an economic position (Esser, 2001, p. 1618).

These dimensions can be applied to individuals or groups to assess their social integration status. Esser's social integration dimensions have also been applied to the context of media use and migrants to analyze the effect of media use on integration (Brendler et al., 2013). But what has not been done so far, is to distinguish between social integration offline and online on the assumption that the use of social media leads to a form of social integration in a virtual community which might in turn relate to social integration in society. 


\section{Interdisciplinary Concept Integration}

Esser's social integration dimensions are merged with Berry's acculturation model. The approach of combining these social integration dimensions with the acculturation typology is as such not a new approach. In one of his studies, Esser applies Berry's typology to his social integration dimensions and empirically tested this integrated model using data from the German Socio-Economic Panel (GSOEP) (Esser, 2009). To avoid conceptual confusion, Esser re-names Berry's acculturation strategy outcome of "integration" into "multiple inclusion". Furthermore, Esser and Berry both use the term acculturation. Berry only focuses on the aspect of acculturation to define four strategies to deal with a new culture. Esser extends Berry's typology of acculturation, which is one of four dimensions of social integration, to the other three dimensions, namely interaction, identification, and placement (Figure 2).

Figure 2. Integration of Esser's Social Integration Dimensions and Berry's Acculturation Strategies

\section{Typology of Social Integration}
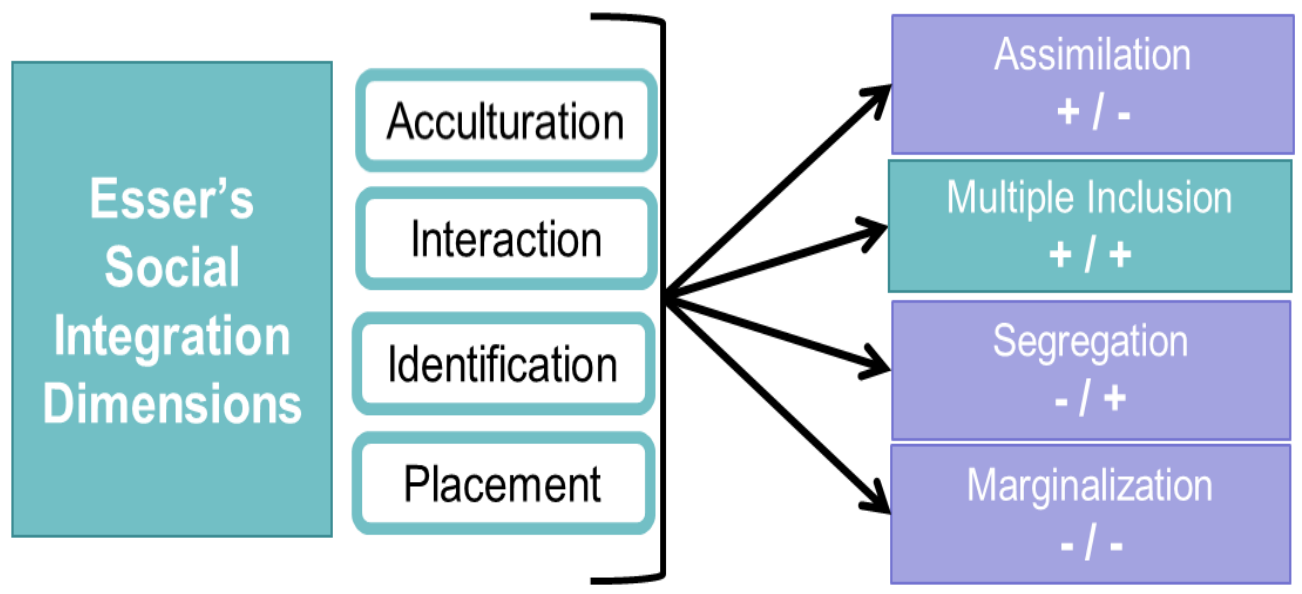

Source: Own illustration, based on Esser (2009, p. 362, Fig. 2) and Berry et al. (2006, p. 306).

The concept integration results in a typology of social integration. For each of Esser's social integration dimension one of the four outcomes described by Berry can be assigned. For instance, in the interaction dimension the outcome of assimilation would be assigned if an individual or a group only has social relations with people from the new "host" society and no social relations to people from their old "home" society. The opposite outcome for the interaction dimension would be segregation, which would mean that an individual or a group has no social relations with people from the new "host" society but only social relations to people from their old "home" society.

So far, the conceptual starting point of the integrated typology proposed here is similar to what has been done before in research. However, the focus 
and context here is different. As social media use is of the central interest, social integration is extended to the online world. Previous research presents ambiguous results about the relation between the offline and online world. Earlier studies from the times when social media just emerged, present results where offline friends are simply mirrored online. This means that people connect to others online only when they have already an offline connection (Lampe, Ellison, \& Steinfield, 2006; Ellison, Steinfield, \& Lampe, 2007). More recent studies show that online networks differ from offline networks and even influence each other (Subrahmanyam, Reich, Waechter, Espinoza, 2008; Lehdonvirta \& Räsänen, 2010). Therefore, it is important to make a clear distinction between the offline and online world in order examine the interaction and relationship between the two worlds and determine whether there is a difference in the integration strategy.

Thus, it is distinguished between the social integration taking place in society which would be offline context, and social integration happening in virtual communities using social media which would be online context. This distinction between the offline and online world is crucial here, as through social media users might follow a different integration strategy online than offline, because different opportunities are offered (e.g. in terms of type of social relations or language use).

As depicted in Figure 3 the social integration dimensions used in context of the "offline" society, can also be applied to the "online" context of social media. The acculturation dimension, which encompasses cultural aspects, can be assessed through the language that is used both in the offline and online environment. The interaction dimension, which refers to social relations, can be measured by asking about face-to-face friendships and online communication partners, always with reference to the ethnic background of these social relations. As for the identification dimension, this can be measured through the subjective feeling of belonging to a certain ethnic group in the real world and to a specific ethnic online community. These four social integration dimensions for the online context can then be also assigned to a specific outcome (assimilation, multiple inclusion, segregation, and marginalization). Thus, the indicators defining the social integration strategies can be perfectly applied to social integration both offline and online. This allows a comparison that offers important insights into the social integration taking place offline and online (Figure 3). 
Figure 3. Social Integration in the Offline and Online Context

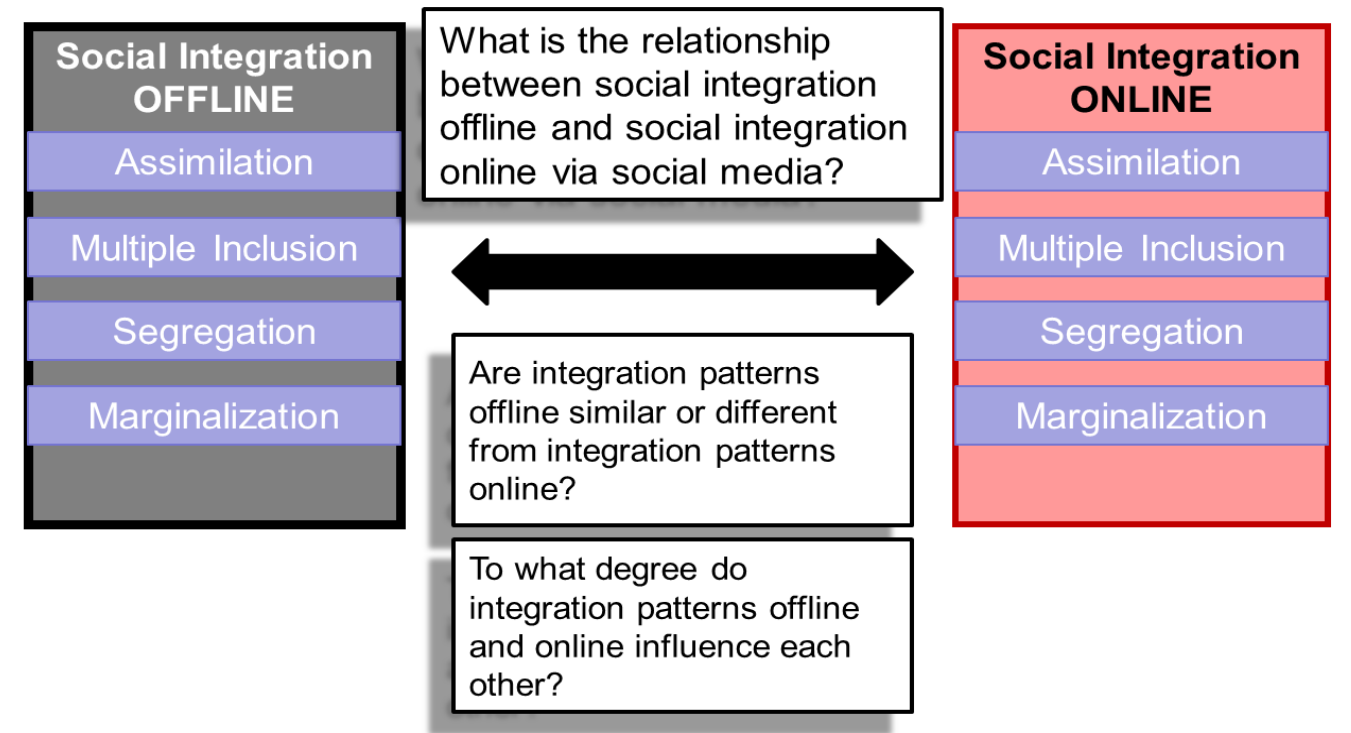

Source: Own illustration.

By having these two distinct contexts it is possible to examine the relationship of social integration offline and online in terms of similarities, differences, or even direction of influences. This interdisciplinary approach with the specific distinction of offline and online social integration allows for a more comprehensive understanding on the relationship between social media use and integration of ethnic minorities.

\section{Discussion and Conclusions}

The relationship between social media use and the integration of ethnic minorities is still an under-research field. The interdisciplinary concept integration proposed in this paper attempted to expand current integration research to social media use of ethnic minorities. By integrating theories and concepts from media and communication studies, sociology, and psychology, a new framework appropriate for assessing the relationship between social media use and integration was presented. A typology of social integration has been described and extended to the social media context. Consequently, a clear distinction has been made between the offline and online world. As social media allows for social interaction on a transnational level, different options for engaging in a (virtual) community are available. This might result in different social integration strategies online than offline. Therefore, a distinction between social integration that happens in the "online" community and social integration that takes place in the "offline" society is crucial for understanding the role social media play in the integration of ethnic minorities. The overall aim of this paper was to enrich the conceptual foundations of integration research and to provide a framework for further empirical research in this field. 


\section{References}

Berry, J. W., Phinney, J. S., Sam, D. L., \& Vedder, P. (2006). Immigrant youth: Acculturation, identity, and adaptation. Applied Psychology: An International Review, 55(3), 303-332.

Brendler, A.-H., Jöckel, S., Niemann, F., Peter, S., Schneider, H., Stiebeling, H., et al. (2013). Die Rolle der Individual- und Massenmedien im Integrationsprozess von Jugendlichen mit Migrationshintergrund [The Role of Individual and Mass Media in the Process of Adolescent Immigrant's Social Integration]. Publizistik, 161178.

Cabssa, L. J. (2003). Measuring Acculturation: Where We Are and Where We Need to Go. Hispanic Journal of Behavioral Science (25), 127-146.

Ellison, N. B., Steinfield, C., \& Lampe, C. (2007). The benefits of Facebook "friends": Social capital and college students' use of online social network sites. Journal of Computer-Mediated Communication, 1143-1168.

Esser, H. (2001). Integration und Ethnische Schichtung [Integration and Ethnic Stratification]. Mannheim: Mannheimer Zentrum für Europäische Sozialforschung [Mannheim Centre for European Social Research].

Esser, H. (2009). Pluralisierung oder Assimilation? Effekte der multiplen Inklusion auf die Integration von Migranten [Pluralization or Assimilation? Effects of Multiple Inclusion on the Integration of Immigrants]. Zeitschrift für Soziologie [Journal for Sociology] (5), 358-378.

Geißler, R., \& Weber-Menges, S. (2009). Media Reception and Ideas on Media Integration among Turkish, Italian and Russo-German Migrants in Germany. In R. Geißler, \& H. Pöttker (Eds.), Media - Migration - Integration: European and North American Perspectives (pp. 27-43). Bielefeld: transcript Verlag.

Grieve, R., Indian, M., Witteveen, K., Tolan, G. A., \& Marrington, J. (2013). Face-toface or Facebook: Can social connectedness be derived online? Computers in Human Behavior, 604-609.

Kaplan, A. M., \& Haenlein, M. (2010). Users of the world, unite! The challenges and opportunities of Social Media. Business Horizons(53), 59-68.

Katz, E., Blumer, J. G., \& Gurevitch, M. (1974). Utilization of Mass Communication by the Individual. In J. G. Blumer (Eds.), The Uses of Mass Communications: Current Perspectives on Gratifications Research (pp. 19-32). Beverly Hills, CA: SAGE.

Lampe, C., Ellison, N., \& Steinfield, C. (2006). A Face(book) in the Crowd: Social Searching vs. Social Browsing. 20th Anniversary Conference on ComputerSupported Cooperative Work (CSCW 2006) (pp. 167-170). New York: NE: ACM Press.

Lehdonvirta, V., \& Räsänen, P. (2010). How do young people identify with online and offline peer groups? A comparison between UK, Spain and Japan. Journal of Youth Studies, 1-18.

Mejias, U. A. (2010). The limits of networks as models for organizing the social. New Media \& Society, 12(4), 603-617.

Müller, T., \& Beisch, N. (2011). Onlinenutzung von Migranten [Online Usage of Migrants]. Media Perspektiven 10, 493-503.

Park, N., Song, H., \& Lee, K. M. (2014). Social networking sites and other media use, acculturation stress, and psychological well-being among East Asian college students in the United States. Comuters in Human Behavior (36), 138-146. 
Peeters, A., \& d'Haenens, L. (2005). Bridging or bonding? Relationships between integration and media use among ethnic minorities in the Netherlands. Communications, 30(2), 201-23.

Piga, A. (2007). Mediennutzung von Migranten: Ein Forschungsüberblick [Media Usage of Migrants: A Literature Review]. In H. Bonfadelli, \& H. Moser (Eds.), Medien und Migration. Europa als multikultureller Raum?[Media and Migration. Europe as an intercultural space?] (pp. 209-234). Wiesbaden: VS Verlag für Sozialwissenschaften [Publisher for Social Sciences].

Raacke, J., \& Bonds-Raacke, J. (2008). MySpace and Facebook: Applying the Uses and Gratifications Theory to Exploring Friend-Networking Sites. CyberPsychology \& Behavior, 11(2), 169-174.

Sawyer, R., \& Chen, G. (2012). The impact of social media on intercultural adaptation. Intercultural Communication Studies, 21(2), 151-169.

Shuter, R. (2011). Introduction: New Media Across Cultures - Prospect and Promise. Journal of International and Intercultural Communication, 241-245.

Statistisches Bundesamt. (2013). Bevölkerung und Erwerbstätigkeit: Bevölkerung mit Migrationshintergrund - Ergebnisse des Mikrozensus 2013 [Population and Employment: Population with Migration Backgrounds - Results of the Microcensus 2013]. Wiesbaden: Statistisches Bundesamt [Federal Office of Statistics].

Subrahmanyama, K., Reich, S. M., Waechter, N., \& Espinoza, G. (2008). Online and offline social networks: Use of social networking sites by ermerging adults. Journal of Applied Developmental Psychology, 420-433.

Trebbe, J. (2007). Types of Integration, Acculturation Strategies and Media Use of Young Turks in Germany. Communications (32), 171-191.

Weiss, H.-J., \& Trebbe, J. (2001). Mediennutzung und Integration der türkischen Bevölkerung in Deutschland. Ergebnisse einer Umfrage des Presse- und Informationsamtes der Bundesregierung [Media Usage and Integration of the Turkish Population in Germany. Survey Results from the Press and Information Office of the German Federal Government]. Potsdam: GöfaK Medienforschung.

Worbs, S. (2010). Mediennutzung von Migranten in Deutschland [Media Usage of Migrants in Germany]. Working Paper 34. Nürnberg: Bundesamt für Migration und Flüchtlinge [Federal Office for Migration and Refugees]. 
